\title{
The Influence of Gear Modification on Transmission Noise Based on Romax
}

\author{
Kang Tengteng ${ }^{1, a}$, Wang Shuhan ${ }^{1, b^{*}}$, Su Chengyun ${ }^{1, c}$, Gao Xiaoguang ${ }^{2, d}$ and \\ Yu Xintao ${ }^{2, \text { e }}$ \\ ${ }^{1}$ Department of Automobile Engineering, Beijing University of Aeronautics and Astronautics, Beijing \\ 100083, China \\ ${ }^{2}$ Engineering Technology Research Center, Shengrui Transmission Corporation Limited, Weifang \\ 261205, China

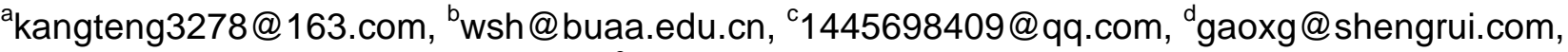 \\ eyuxt@shengrui.com
}

Keywords: gear modification; mesh misalignment; transmission error

Abstract. The transmission noise is serious in five speed condition. The problematic gears of transmission are confirmed by bench noise test. The model of transmission are built and systematically analyzed with Romax software. Adjusting multi-parameters of gears in the target of reduce transmission error, mesh misalignment and load on tooth, and then testing the noise in vehicle to verity the effective of modification. The results after optimization indicate the values of mesh misalignment and loads on tooth are decreased obviously, and the sound pressure level of vehicle declines $4 \mathrm{~dB}$.

\section{Introduction}

The paired gears deflect the theoretic meshing line due to the factors of gear transmission error and gear teeth deformation when the gears drive, so there will generate impact or interfere between the gear teeth, and then produce excited force and lead to vibration of transmission system, it will cause resonation and noise when the vibration is transmitted to the housing. For now, the gear modification are assumed to be the most effective method to decrease transmission noise ${ }^{[1][2]}$, the research methods of gear modification are improving day by day, the widespread methods mainly include FEM(finite element method), function method of building modified teeth curve, elastic mechanics method, formula method etc. ${ }^{[3][4][5][6]}$. The research subject of this article is a 8-speed automatic transmission (8AT), and then using the method of gear modification resolves noise issue after determining the noise source in five speed. It can provide a valid measure about controlling transmission noise.

\section{Determining the noise source}

\section{The basic structure of 8AT}

The basic layout scheme and structure of 8AT is shown in Figure 1, the transmission adopts two-axis structure, three planet row, three pairs of cylindrical gears and five shift controlling elements (one brake and four clutches) to achieve eight forward gears and one reverse gear.

The gear mesh frequency can be obtained based on the transmission gears geometric parameters,

$$
f=Z \times \frac{n}{60} .
$$

$f$ is the meshing frequency $(\mathrm{Hz}) ; \mathrm{Z}$ is the number of teeth; $\mathrm{n}$ is rotating speed of gear(rpm).

Setting the input shaft speed is $60 \mathrm{rpm}$, the gear mesh frequency is equal to the corresponding gear order. Table 1 shows gear mesh frequency. 
Table 1, Gear mesh frequency in five speed conditions

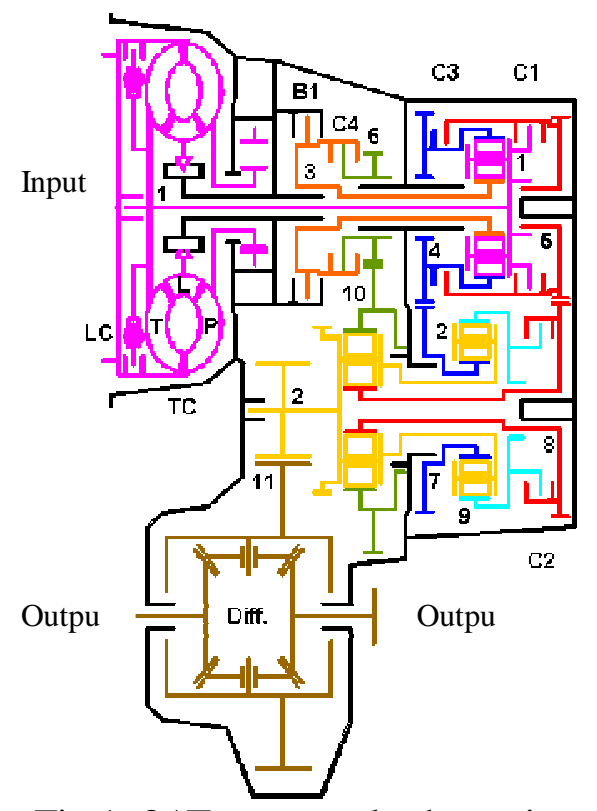

Fig.1, 8AT structural schematic

\begin{tabular}{c|c}
\hline Element & Gear Frequency $[\mathrm{Hz}]$ \\
\hline Gear 6 & 106.6 \\
\hline Gear 4 & 66.3 \\
\hline Ring 1 & 50.9 \\
\hline Sun 1 & 89.1 \\
\hline Planet 1 & -38.1 \\
\hline Gear 5 & 118.0 \\
\hline Gear 8 & -118.0 \\
\hline Ring 2 & -98.0 \\
\hline Sun 2 & -28.3 \\
\hline Planet 2 & -14.3 \\
\hline Gear 7 & -66.3 \\
\hline Gear 10 & -106.6 \\
\hline Sun 3 & -23.0 \\
\hline Ring 3 & -59.0 \\
\hline Planet 3 & 3.4 \\
\hline Differential Gear & 21.3 \\
\hline Oil Pump Gear & 11 \\
\hline
\end{tabular}

\section{NVH bench test of transmission}

The bench test of vibration and noise include unload and load conditions in all gears. Test equipment include 3560C data acquisition front-end, Dell Pc machine, PULSE14.0 analysis software, $\mathrm{B} \& \mathrm{~K}$ microphones and acceleration sensors, the arrangement of microphones and position sensors are shown in Fig.2.

The transmission on the bench test doesn't produce whine noise in subjective feeling. We can find that the peak value of total curve noise is $8 \mathrm{~dB}$ higher than normal value in five-speed $120 \mathrm{Nm}$ slow acceleration conditions, and the corresponding rotating speed is between 2500rpm and 3200rpm, at the same time the noise value of 106.6 order (red curve) is higher than others and contribute large to the total noise value, and the 106.6 order is the frequency of gear 6 and gear 10 from Tab.1.Test data analysis indicates that the noise peak value is not obvious when gear6 and gear 10 are unloaded, and the noise peak value is obvious when gear 6 and gear 10 are loaded. Therefore, we confirm that the mesh excitation of gear 6 and gear 10 are the main noise source. Figure 3 is the noise slice map in five-speed $120 \mathrm{Nm}$ slow acceleration conditions.

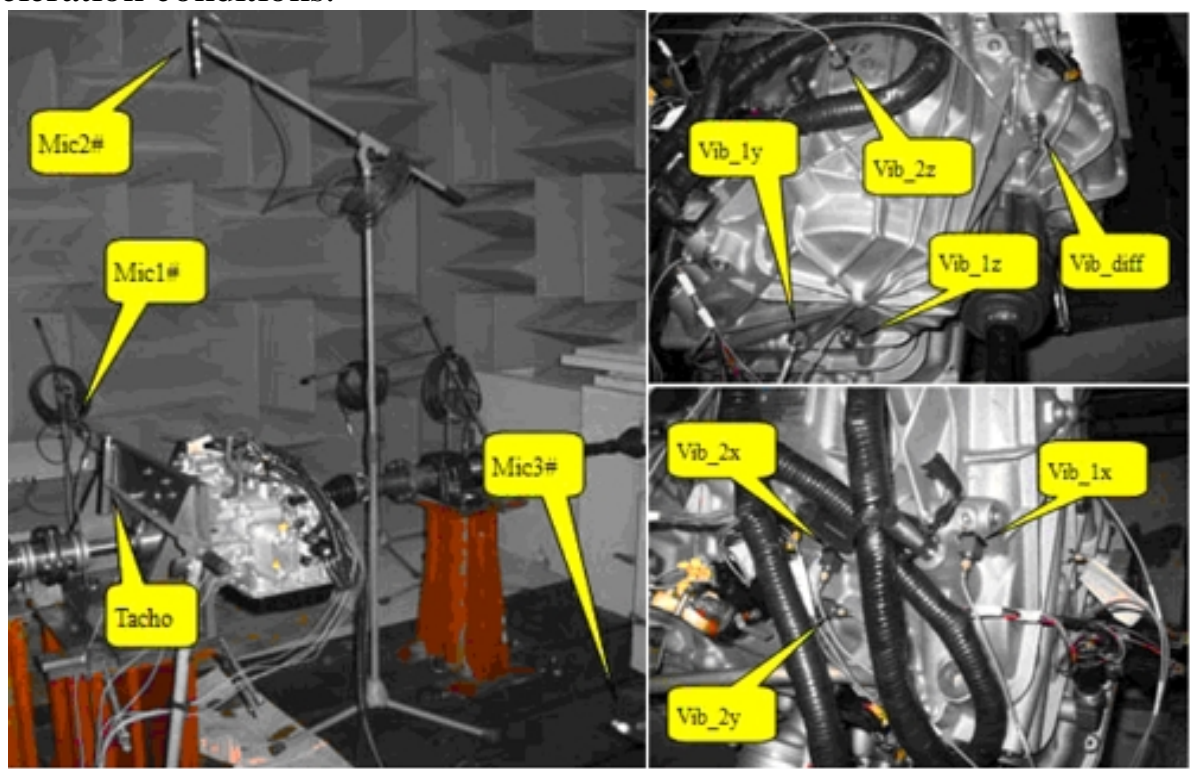

Fig.2, The mounting positions of microphones and sensors 


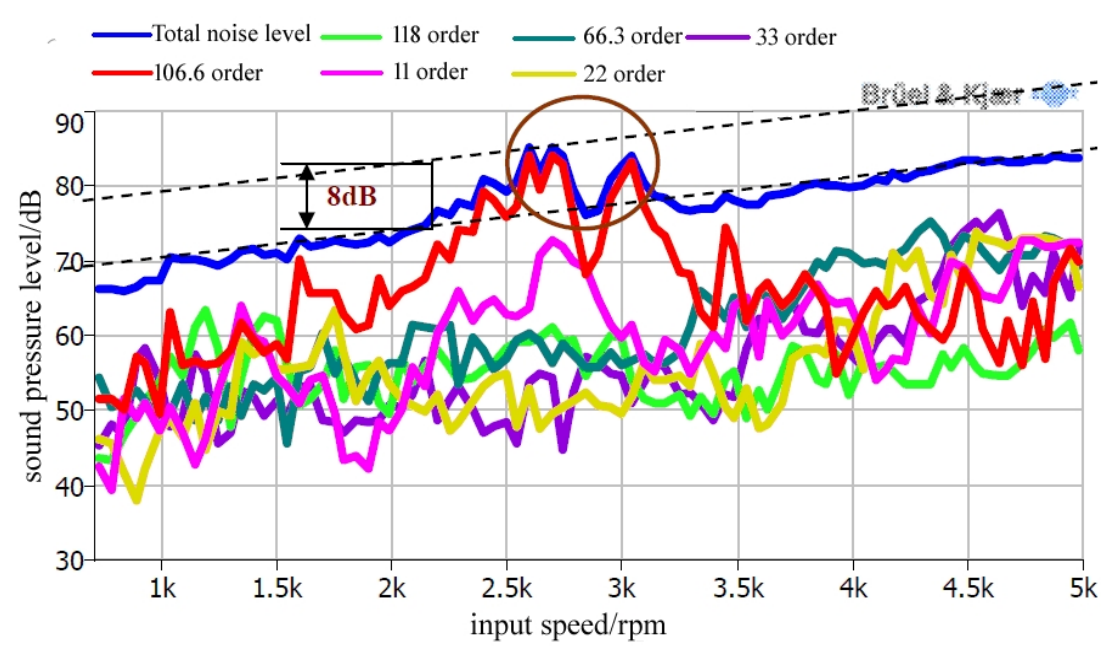

Fig.3, Slice map of acceleration code in five speed

\section{Gear Modification}

\section{gear involute modification}

The base pitches of meshing involute gears are equal in ideal gear transmission, but the base pitches may be not equal due to elastic deformation of teeth in actual situation. Because gear manufacturing error and thermal deformation, if the base pitch of driving gear is less than the driven gear's, and the conflict are generated when tooth mesh in, otherwise the conflict are generated when tooth mesh out ${ }^{[7]}$. The common method is gear profile modification to eliminate the conflict, changing the shape of tooth in the addendum tooth profile and tooth root fillet can effectively eliminate conflict. The methods of tip relief, gear tooth modification can reduce tooth conflict and tooth load, and improve the capability of teeth ${ }^{[8][9]}$.

\section{gear lead modification}

The ideal gear contact is symmetrical contact over the full length of the tooth width direction, while it is difficult to achieve this status because of unavoidable factors, like manufacture error, installation error and elastic deformation etc ${ }^{[10]}$. It is easy to produce gear partial load and decrease tooth surface load capability. For now, many methods and standards are given in different countries and scholars, like ISO, GAMA and kinds of calculated formula etc. They can effectively improve gear meshing status, reduce meshing impact and increase transmission stability, but there are no generally applicable methods for tooth lead modification ${ }^{[11]}$. Gear elastic deformation, thermal deformation are difficult to measure and calculate, manufacture error and installation error exist randomness, we need to choose and adjust different methods based on actual condition or test.

\section{Modeling and Analysis}

In this paper, Romax Designer is used to build and analyze the eight-speed automatic transmission model. The input shaft, output shaft and intermediate shaft of transmission are parametric modeling by design drawings, and then determining bearings position on shafts and gears position on bearings. All bearings can be chosen from bearing database or can be custom as required. The gears are needed to make detailed model, the parameters of gear 6 and gear 10 are shown in Tab.2. The finite element model of gearbox housing, planet carrier and other complex flexible parts are built with Hyper Mesh and then import Romax software. The position of these parts are confirmed by corresponding bearings, these parts are connected and integrated to bearing by editing nodes in Romax Designer, their position are confirmed by connected bearings. The completed simulation model is shown in Figure 4. 


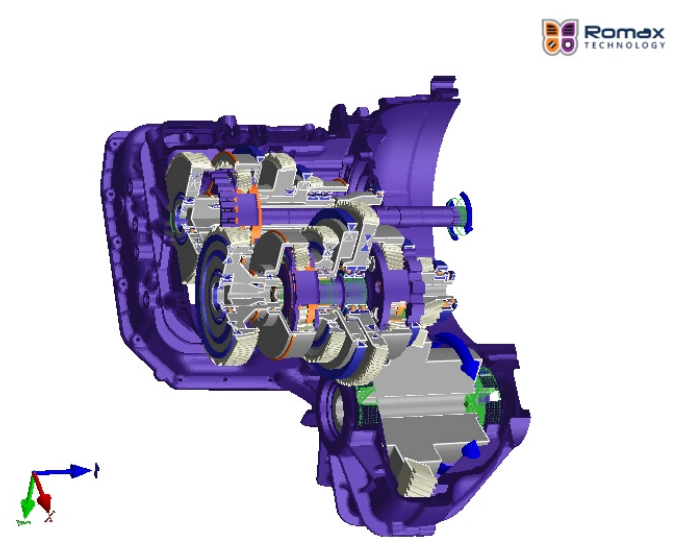

Fig.4, Transmission simulation model

Table 2, The parameters of gear 6 and gear 10

\begin{tabular}{c|c|c|c|c|c}
\hline & Module & Number of teeth & Pressure angle $\left[{ }^{\circ}\right]$ & Helical angle ${ }^{\circ}{ }^{\circ}$ & Tooth width [mm] \\
\hline Gear 6 & 1.3 & 61 & 17.5 & 18 & 15 \\
\hline Gear 10 & 1.3 & 132 & 17.5 & 18 & 14 \\
\hline
\end{tabular}

The parameters and operating condition of simulation model are confirmed to consistent with tested transmission. The power in and power out are defined in transmission input shaft and output shaft, the input speed is defined 3000rpm, and input torque is $120 \mathrm{Nm}$ in five-speed condition.

The stiffness and mass matrices of transmission housing can be got from condensing FE model, then making static analysis and power analysis for the entire model. The targeted gears (gear6 and gear 10) are analyzed in micro geometry based the parameters in Table 3.

Table 3. Gears micro parameters before optimization

\begin{tabular}{c|c|c|c|c}
\hline & \multicolumn{2}{|c|}{ involute modifications } & \multicolumn{2}{c}{ lead modifications } \\
\hline & $\begin{array}{c}\text { Involute } \\
\text { barreling[ }[\mu \mathrm{m}]\end{array}$ & $\begin{array}{c}\text { Involute } \\
\text { slope[ } \mu \mathrm{m}]\end{array}$ & $\begin{array}{c}\text { Lead } \\
\text { crown[ } \mu \mathrm{m}]\end{array}$ & $\begin{array}{c}\text { Lead } \\
\text { slope }[\mu \mathrm{m}]\end{array}$ \\
\hline Gear 6 & $0 \pm 7$ & 0 & $9.0 \pm 3$ & $0 \pm 7$ \\
\hline Gear 10 & $0 \pm 7$ & 0 & $3.0 \pm 3$ & $0 \pm 7$ \\
\hline
\end{tabular}

The mesh misalignment of gear pair (gear 6 and gear 10) is $-6.89 \mu \mathrm{m}$, the minus indicates negative opening angle displacement along the $\mathrm{Z}$ axis of Romax. Fig.5 shows the gear linear transmission error which maximal value is $14.21 \mu \mathrm{m}$ and the minimum value is $13.58 \mu \mathrm{m}$, the difference between the two values is $0.63 \mu \mathrm{m}$. Fig. 6 shows tooth flank load distribution of gear 6 , the phenomenon of tooth partial load is obvious and the normal maximal value of per unite length is up to $46.619 \mathrm{~N} / \mathrm{mm}$.

\section{The results of gears optimization}

Optimizing gear transmission error and tooth flank load distribution is the target of gear modification in Romax, the range values of gear parameters which are shown in Table 4 can be got according to compositely adjustment. The range values consider the manufacture error and installation error, and all the results which are given in paper are optimal results of the range values.

The maximum value of transmission error is $0.61 \mu \mathrm{m}$ in Fig.7, and the gear mesh misalignment decreased to $-2.82 \mu \mathrm{m}$, the maximum value of tooth normal load per unit length is $32.101 \mathrm{~N} / \mathrm{mm}$ which is shown in Fig8. The mesh misalignment of gear 6 and gear 10 is being reduced $4.07 \mu \mathrm{m}$ after optimization, the maximum value of transmission error is small, the maximum value of tooth normal 
load per unit length decrease $14.518 \mathrm{~N} / \mathrm{mm}$, the phenomenon of gear partial load disappear and the contact area is good.

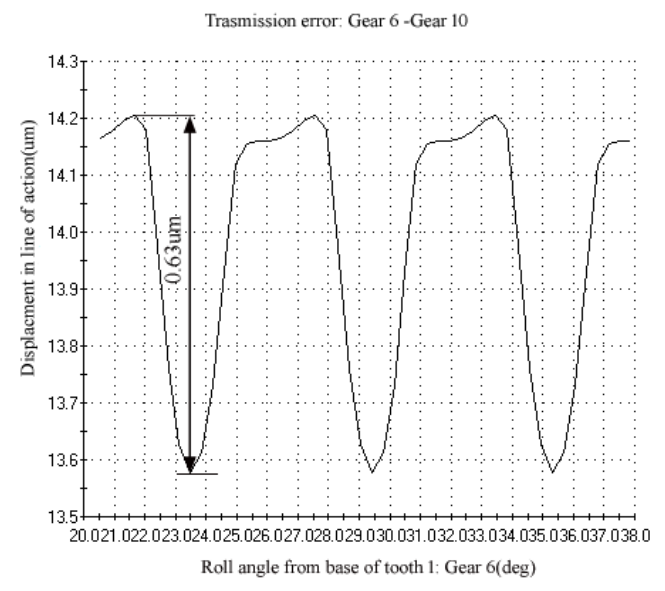

Fig.5 The transmission error of gear 6 and gear 10 before optimization
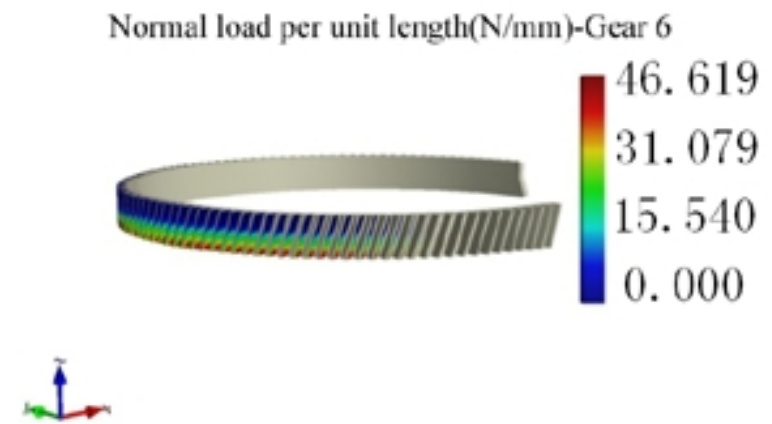

Fig. 6 The tooth normal load of gear 6 before optimization

Table 4, Gears micro parameters after optimization

\begin{tabular}{c|c|c|c|c}
\hline & \multicolumn{2}{|c|}{ involute modifications } & \multicolumn{2}{c}{ lead modifications } \\
\hline & $\begin{array}{c}\text { Involute } \\
\text { barreling[ } \mu \mathrm{m}]\end{array}$ & $\begin{array}{c}\text { Involute } \\
\text { slope[ } \mu \mathrm{m}]\end{array}$ & $\begin{array}{c}\text { Lead } \\
\text { crown[ } \mu \mathrm{m}]\end{array}$ & $\begin{array}{c}\text { Lead } \\
\text { slope }[\mu \mathrm{m}]\end{array}$ \\
\hline Gear 6 & $1.5 \pm 1$ & $-1.5 \pm 5$ & $1.2 \pm 1$ & $1.0 \pm 5$ \\
\hline Gear 10 & $1.5 \pm 1$ & $-1.5 \pm 5$ & $1.5 \pm 1$ & $1.0 \pm 5$ \\
\hline
\end{tabular}

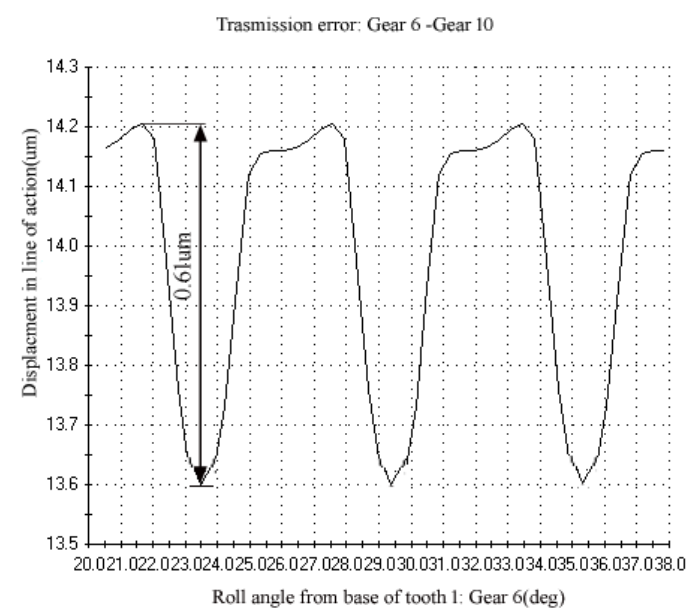

Fig.7 The transmission error of gear 6 and gear 10 after optimization 


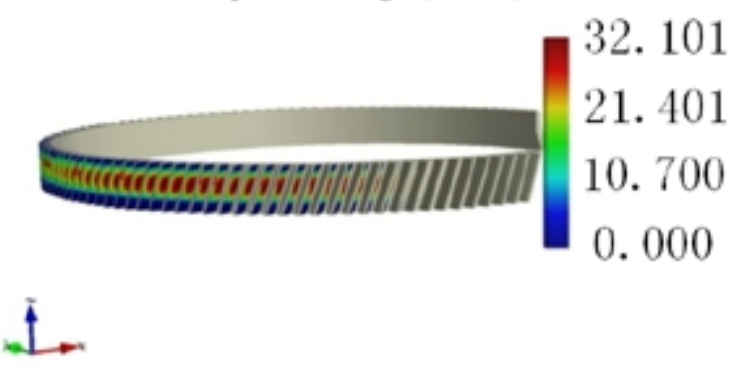

Fig. 8 The tooth normal load of gear 6 before optimization

\section{Vehicle Noise Experiment}

Using vehicle noise experiment tests the availability of gear modification. This test can collect signal of magnetoelectric speed sensor which is arranged in engine crankshaft to get engine speed signal, acoustic sensors which are installed near the driver's ear in the cab, and vibration sensors are installed on the gearbox. The specific location of vibration sensors are shown in Table 5. The vibration sensor is PCB three direction sensor, the coordinate system is vehicle coordinate system $+\mathrm{X}+\mathrm{Y}+\mathrm{Z}$. The test work condition are setted in five speed and the software of digital signal processing is LMS test lab.

Table 5, The position of vibration sensors

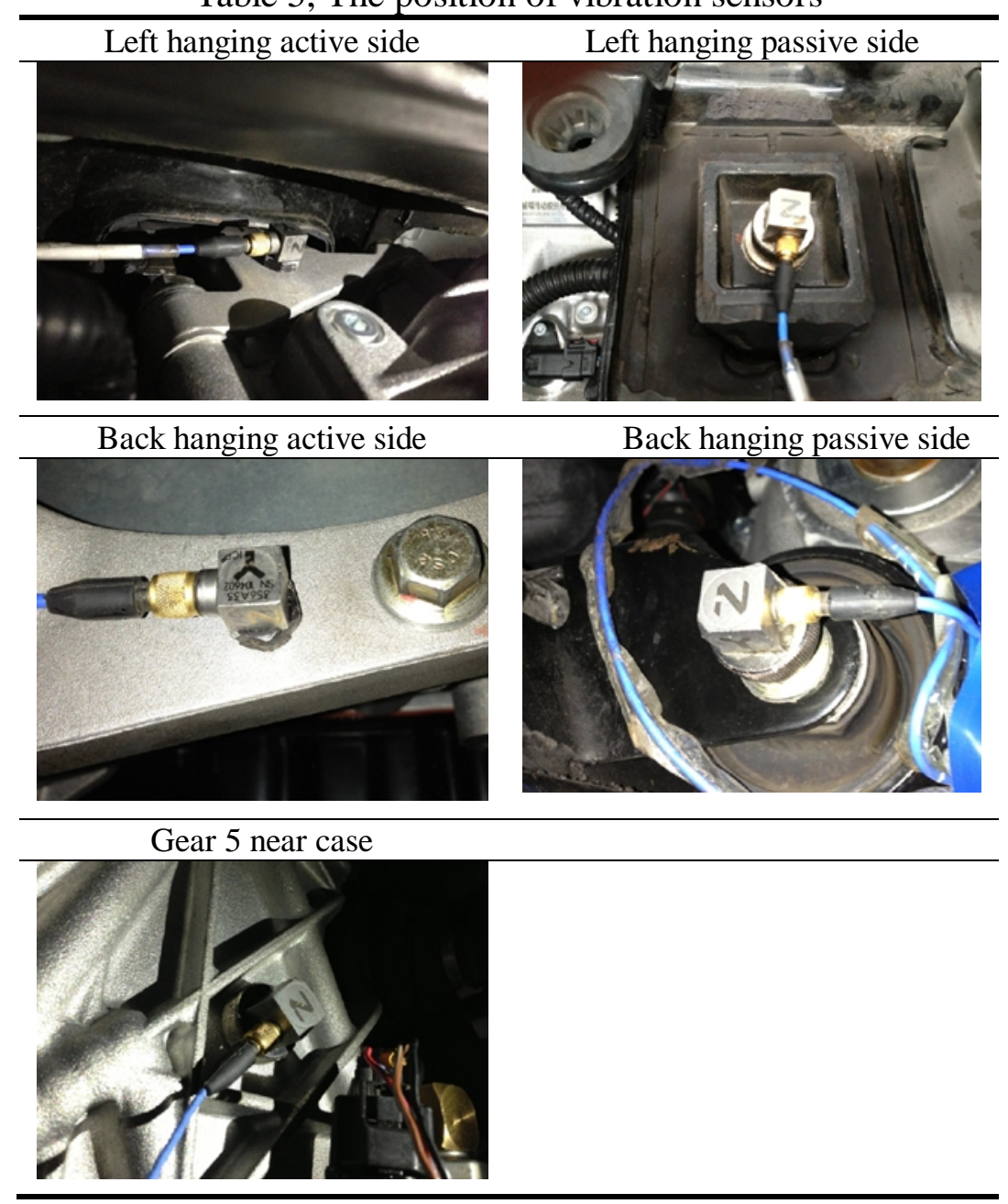


The test results which are shown in Fig.9 indicate that the vehicle total sound pressure level decline $4 \mathrm{~dB}$, and the sound pressure level of gear6 and gear 10 decrease $7 \mathrm{~dB}$ after optimization. The value of noise declines obviously in the range of 1500-2000rpm and 3200-3500rpm.

Transmission error, mesh misalignment and tooth load are optimized targets; compositely adjusting multi-parameter of gears modification in Romax can effectively decline the vehicle noise in practical engineering application.

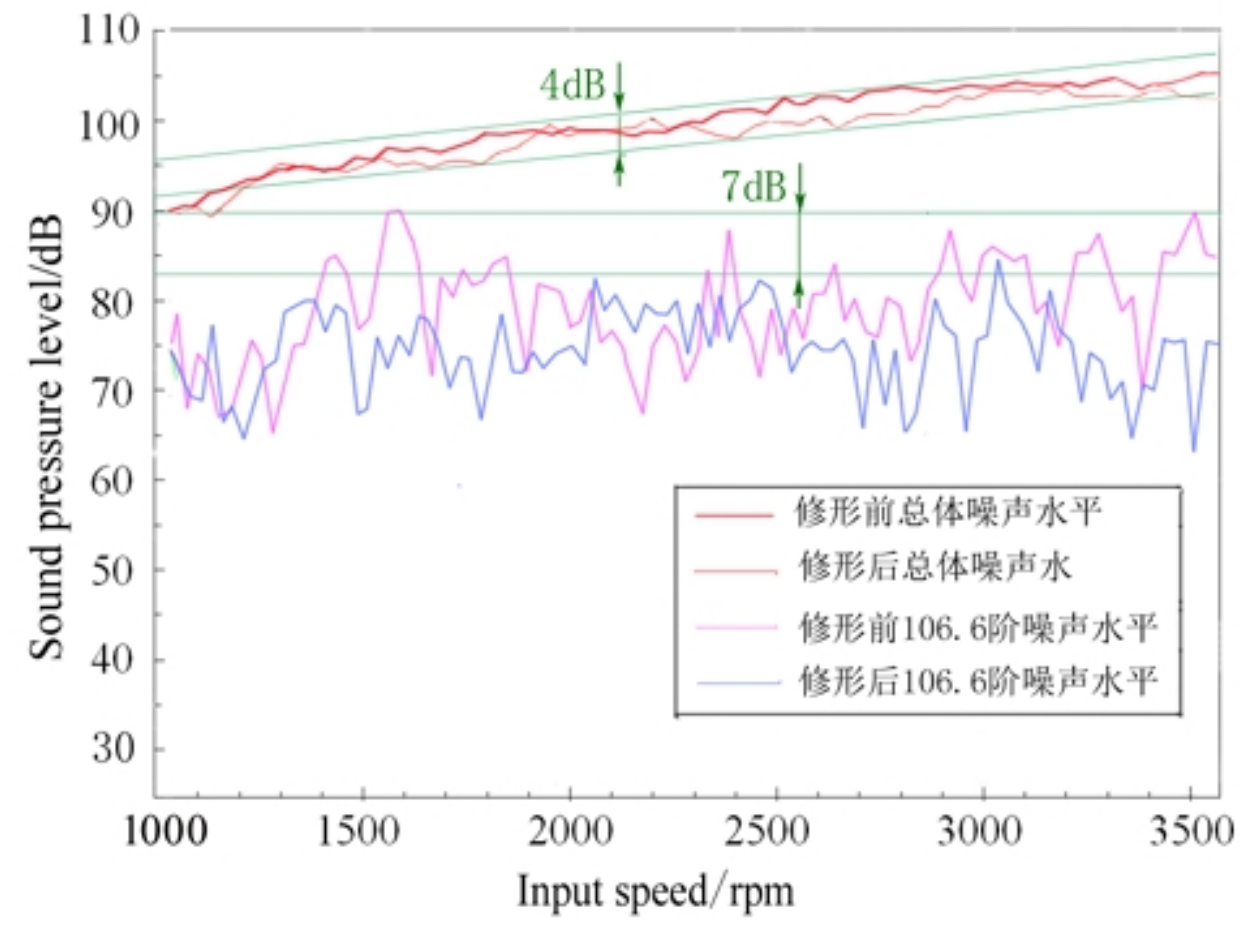

Fig.9 The noise slice map in five speed condition

\section{References}

[1] Uday Nayak, S Aravind, and Sunil Aundhekar. Influence of Gear Geometry on Gearbox Noise Reduction - An Experimental Investigation [J].SAE International, 2014, 7(2): 746-752

[2] Ernesto Rocca, RiccardoRusso. Theoretical and experimental investigations into the influence of the periodic backlash fluctuations on the gear rattle [J]. Journal of Sound and Vibration, 2011, 330(20): $4738-4752$

[3] Jiang Jinke, Fang Zongde. Design and analysis of modified cylindrical gears with a higher-order transmission error [J]. Mechanism and Machine Theory, 2015,88: 141-152

[4] Jianxing Zhou. Gearbox Low-Noise Design Method Based on Panel Acoustic Contribution [J]. Mathematical Problems in Engineering, 2014, (2014): 1-10

[5] F.L. Litvin, A. Fuentes. Gear Geometry and Applied Theory. 2nd Ed. England: Cambridge University Press, 2004

[6] Tang Haichuan, Guo Fen. Gear Screaming Noise Reduction of Automotive Transmission Based on Gear Profile Modification [J]. Journal of University of Shanghai for Science and Technology, 2013, 35(03): 294-299

[7] Sigg, N. Tooth Profile Modification of High Speed Duty Gear// Proceedings of International Conference on Gearing. New York, 1958: 313-316 
[8] Sun Jianguo. Study on the Modification and Dynamic Contact Characteristics of Involute Cylindrical Gears [Dissertation]. Chongqing: Chongqing University, 2008

[9] Runfang Li, Jianjun Wang. Gear system dynamics- vibration, impact, noise [M]. Beijing: Science Press, 1997

[10] Su-Jin Park, Wan-Suk Yoo. Deformation Overlap in the Design of Spur and Helical Gear Pair [J]. Finite Elements in Analysis and Design, 2004, 40(11): 1361-1378

[11] American Gear Manufacturers Association. 6002-B93, Design Guide for Vehicle Spur and Helical Gears, Alexandria, 1993 